\title{
Weibull Deterioration, Quadratic Demand Under Inflation
}

\author{
${ }^{1}$ R. Mohan ${ }^{*},{ }^{2}$ R.Venkateswarlu \\ ${ }^{I}$ Dept of Mathematics, F-Civil, College of Military Engineering Pune - 411031 (INDIA) \\ ${ }^{2}$ GITAM School of International Business GITAM University Visakhapatnam - 530045 (INDIA)
}

\begin{abstract}
Deterministic inventory model is developed for deteriorating products when the demand rate is considered as quadratic function of time, further incorporating two parameter Weibull rate of deterioration with inflation. The model is solved for when shortages are not allowed. A numerical example and sensitivity of the models is also studied at the end.

Key words: Weibull deterioration, Quadratic demand, salvage value, Inflation
\end{abstract}

\section{Introduction}

The assumption of constant, linear, exponential demand rate is not always applicable to many inventory products like vegetables, food stuffs, fashionable clothes, electronic goods, etc., since unstable situations in demand rate. Introducing new items will facinate more in demand during the growth phase of their life cycle. It is evident that, some items may decline due to the introduction of new products due to the choice or influencing customers. So to develop deteriorating inventory models with quadratic demand pattern is worth attempt. Buzacott (1975) developed an EOQ model with inflation.Ghare and Schrader (1963) studied an inventory model for exponentially decaying. Su C.T.,Tong L.I., Tsai S.,(1996) studied an inventory model under inflation for the stock dependent demand consumption rate with exponential decay . Covert and Philip (1973) developed an inventory model for time dependent rate of deterioration. Aggarwal (1978) proposed an order level inventory model for a system with constant rate of deterioration. Dave and Patel (1981) studied a lot size model for time proportional demand with constant deterioration. Deb and Choudhuri (1987) studied a heuristic approach for replenishment of trended inventories with shortages. Hariga (1995) developed an inventory model of deteriorating items for time-varying demand with shortages. Datta and Pal (1991) proposed an EOQ model in the effects of inflation and time value of money with linear time dependent demand rate incorporating shortages. Chakraborti and Choudhuri (1996) proposed an EOQ model for deteriorating items of linear trend in demand with shortages in all cycles. Giri and Chaudhuri (1997) developed a heuristic model for deteriorating items of time varying demand and costs considering shortages. Goyal and Giri (2001) studied survey of recent trend in deteriorating inventory model. Mondal et. al (2003) developed an inventory model of ameliorating items for price dependent demand rate. You (2005) studied the inventory system for the products with price and time dependent demands.

Ajanta Roy (2008) developed an inventory model for deteriorating items with price dependent demand and time varying holding cost with shortages and without shortages. Mishra and Singh (2010) studied an inventory model for deteriorating items with time dependent demand and partial backlogging. Mishra (2012) proposed an inventory model with Weibull rate of deterioration and constant demand. He incorporated variable holding cost with shortages. salvage value also considered for deteriorating items. Vikas Sharma and Rekha (2013) proposed an inventory model for time dependant demand for deteriorating items with Weibull rate of deterioration.In this model shortages are taken consideration. Mohan and Venkateswarlu (2013a) developed an inventory model with variable holding cost and salvage value. Mohan and Venkateswarlu (2013b) proposed an inventory model for quadratic demand with respect to time with salvage considering deterioration items. Mohan and Venkateswarlu(2013c) developed an inventory model with Quadratic Demand, Weibull distribution deterioration rate with Variable Holding Cost and Salvage value. Shital S. Patel,Raman Patel studied an inventory model for deteriorating items with linear demand under permissible delay in payments and inflation in corporating shortages.

In this paper, we consider an inventory model with weibull deterioration rate and demand rate is quadratic function of time. Shortages are not allowed in this case and the time horizon is infinite. The optimal total cost is obtained considering the salvage value for deteriorated items. The numerical example and sensitivity analysis is done at the end. 


\section{Mathematical Assumptions and Notations}

This model is developed using the following assumptions and notations:

i) The demand rate $D(t)$ at time $t$ is assumed to be $D(t)=a t^{2}+b t+c, a \neq 0, b \neq 0, c \geq 0$ Here $c$ is the initial rate of demand, $b$ is the rate with which the demand rate increases and $a$ is the rate with which the change in the rate demand rate itself increases.

ii) The deterioration rate follows two parameter Weibull distribution and is given by $\theta(t)=t^{\beta-1} \alpha \beta \quad ; 0 \leq \alpha \leq 1, \beta \geq 1$.

iii) $\quad \mathrm{D}$, the number of deteriorated units

iv) Replenishment rate is infinite

v) Lead time is zero.

vi) $\quad$, the cost per unit

vii) $Q(t)$ is the inventory level at time $t$

viii) $\quad A$ is the order cost per unit order.

ix) The salvage value $\gamma^{*} \mathrm{C}, 0 \leq \gamma<1$ is associated with deteriorated units during a cycle time.

$\mathrm{x}) \quad \mathrm{R}$, inflation rate

\section{Formulation and solution of the model}

It is assumed that the inventory level depletes as the time passes due to demand rate and deterioration. The differential equation which describes the inventory level at time $t$ can be written as
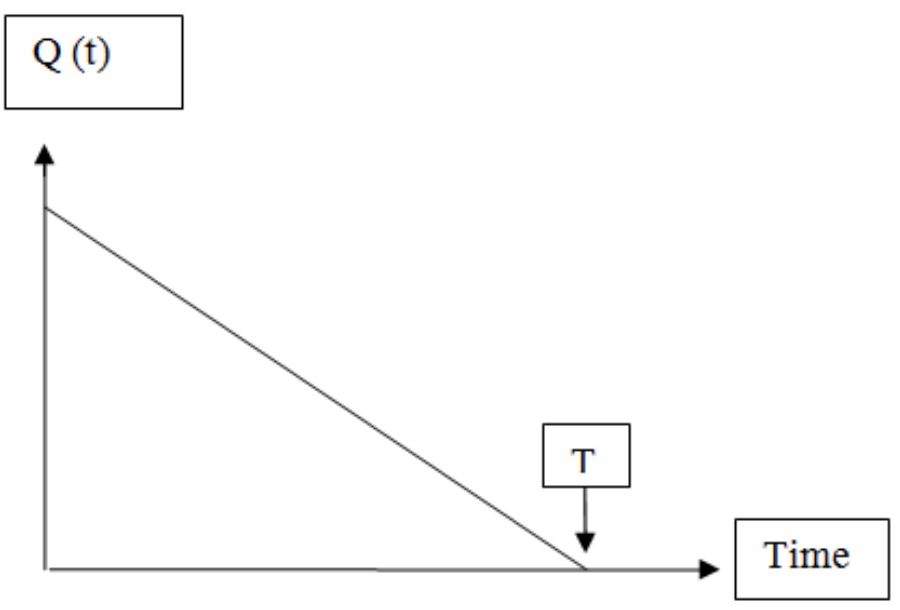

Fig. 1

$$
\begin{gathered}
\frac{d(Q(t))}{d t}+\theta(t) Q(t)=-D(t) ; \theta(t)=t^{\beta-1} \alpha \beta, \quad 0 \leq t \leq T \\
\text { where } \quad D(t)=\left(a t^{2}+b t+c\right) \text {, with } Q(t)=0 \text { at } t=T \\
Q(t) e^{\alpha t^{\beta}}=-\left(\frac{a t^{3}}{3}+\frac{b t^{2}}{2}+c t\right)-\alpha\left(\frac{a t^{\beta+3}}{\beta+3}+\frac{b t^{\beta+2}}{\beta+2}+\frac{c t^{\beta+1}}{\beta+1}\right)+k_{1}
\end{gathered}
$$

where $k_{1}$ is an integral constant. Here we have expanded $e^{\alpha t^{\beta}}$ and ignored higher order terms as $\alpha$ is small.

The solution of the above differential equation using the boundary conditions is given by 


$$
Q(t)=\left\{\begin{array}{l}
\frac{a}{3}\left(T^{3}-t^{3}\right)+\frac{b}{2}\left(T^{2}-t^{2}\right)+c(T-t) \\
+\alpha\left[\begin{array}{l}
\frac{a}{\beta+3}\left(T \beta+3-t^{\beta}+3\right)+\frac{b}{\beta+2}\left(T \beta+2-t^{\beta}+2\right) \\
+\frac{c}{\beta+1}\left(T^{\beta}+1-t \beta+1\right)
\end{array}\right]
\end{array}\right\} e^{-\alpha t^{\beta}}
$$

Since $Q(0)=Q$, we get

$$
Q=\left(\frac{a T^{3}}{3}+\frac{b T^{2}}{2}+c T\right)+\alpha\left[\frac{a T^{\beta+3}}{\beta+3}+\frac{b T^{\beta+2}}{\beta+2}+\frac{c T^{\beta+1}}{\beta+1}\right]
$$

\section{Inventory Model with Salvage value:}

The following costs are calculated to find the total cost of the system when shortages are not allowed: Ordering cost, $(\mathrm{OC})=A$

$$
\begin{aligned}
& \text { Inventory Holding cost, }(\mathrm{IHC})=h \int_{0}^{T} Q(t) e^{-R t} d t
\end{aligned}
$$

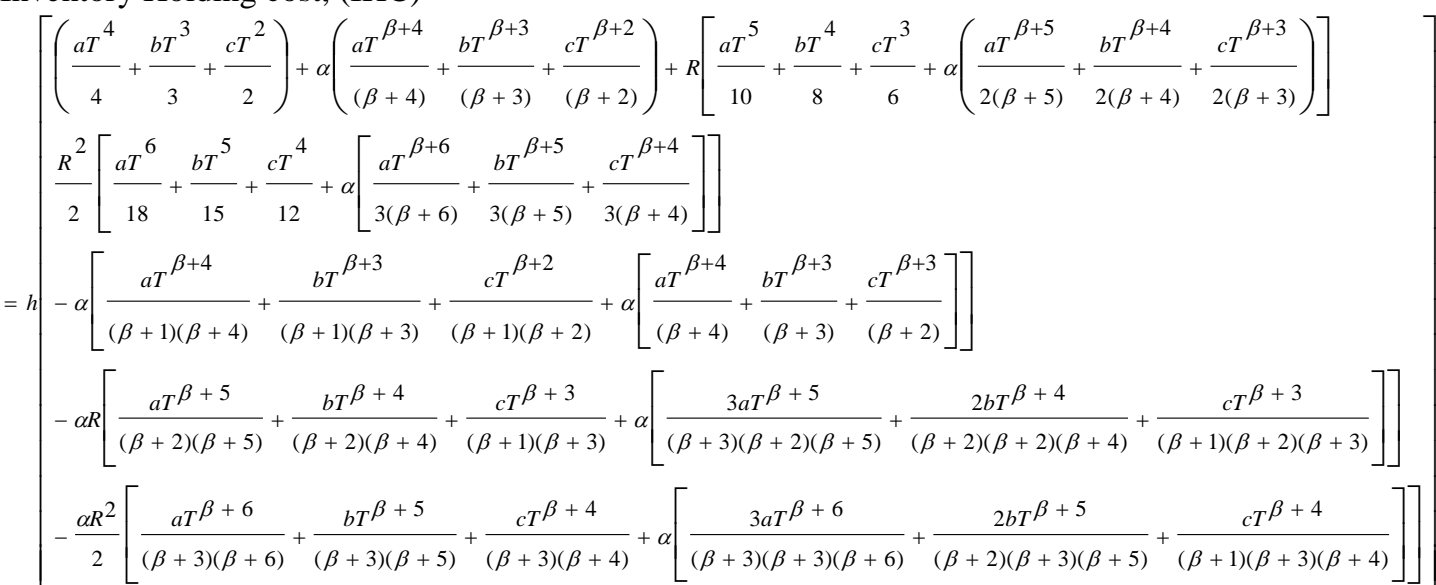

The number of units that deteriorated during this cycle time is

$$
\mathrm{D}=\mathrm{Q}-\int_{0}^{T} D(t) e^{-R t} d t
$$

where $\mathrm{D}(\mathrm{t})=\left(a t^{2}+b t+c\right)$ is the rate of Demand.

Cost due to deterioration $(\mathrm{CD})=$

$$
=C\left[\alpha\left(\frac{a T^{\beta+4}}{(\beta+4)}+\frac{b T^{\beta+3}}{(\beta+3)}+\frac{c T^{\beta+2}}{(\beta+2)}\right)-R\left(\frac{c T^{2}}{2}+\frac{b T^{3}}{3}+\frac{a T^{4}}{4}\right)-\frac{R^{2}}{2}\left(\frac{c T^{3}}{3}+\frac{b T^{4}}{4}+\frac{a T^{5}}{5}\right)\right]
$$

Thus the total cost is obtained as

Total Cost $(\mathrm{TC})=$ Ordering cost + Holding cost + Cost due to deterioration-Salvage value 


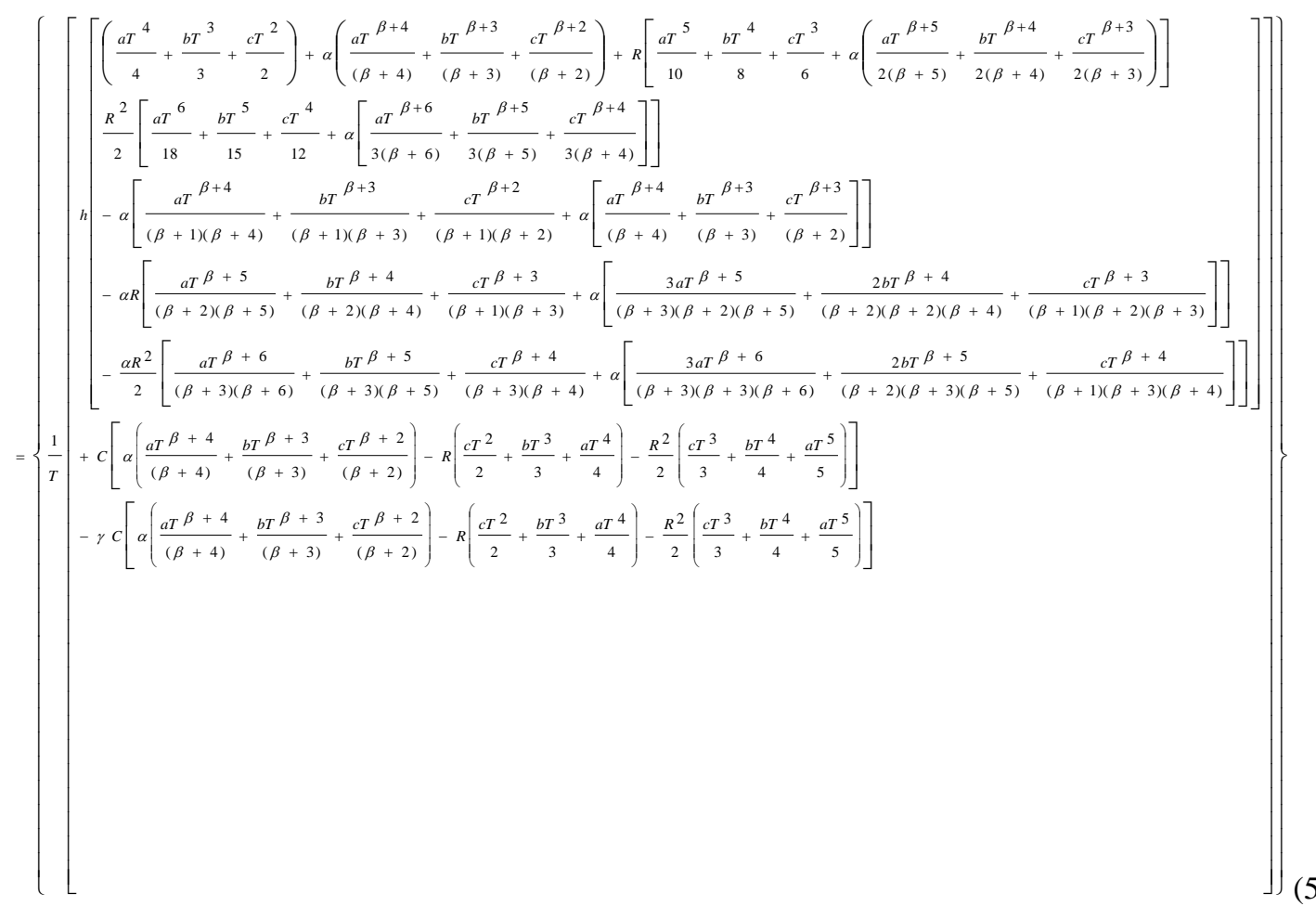

The necessary condition for a minimize total cost per unit time is 


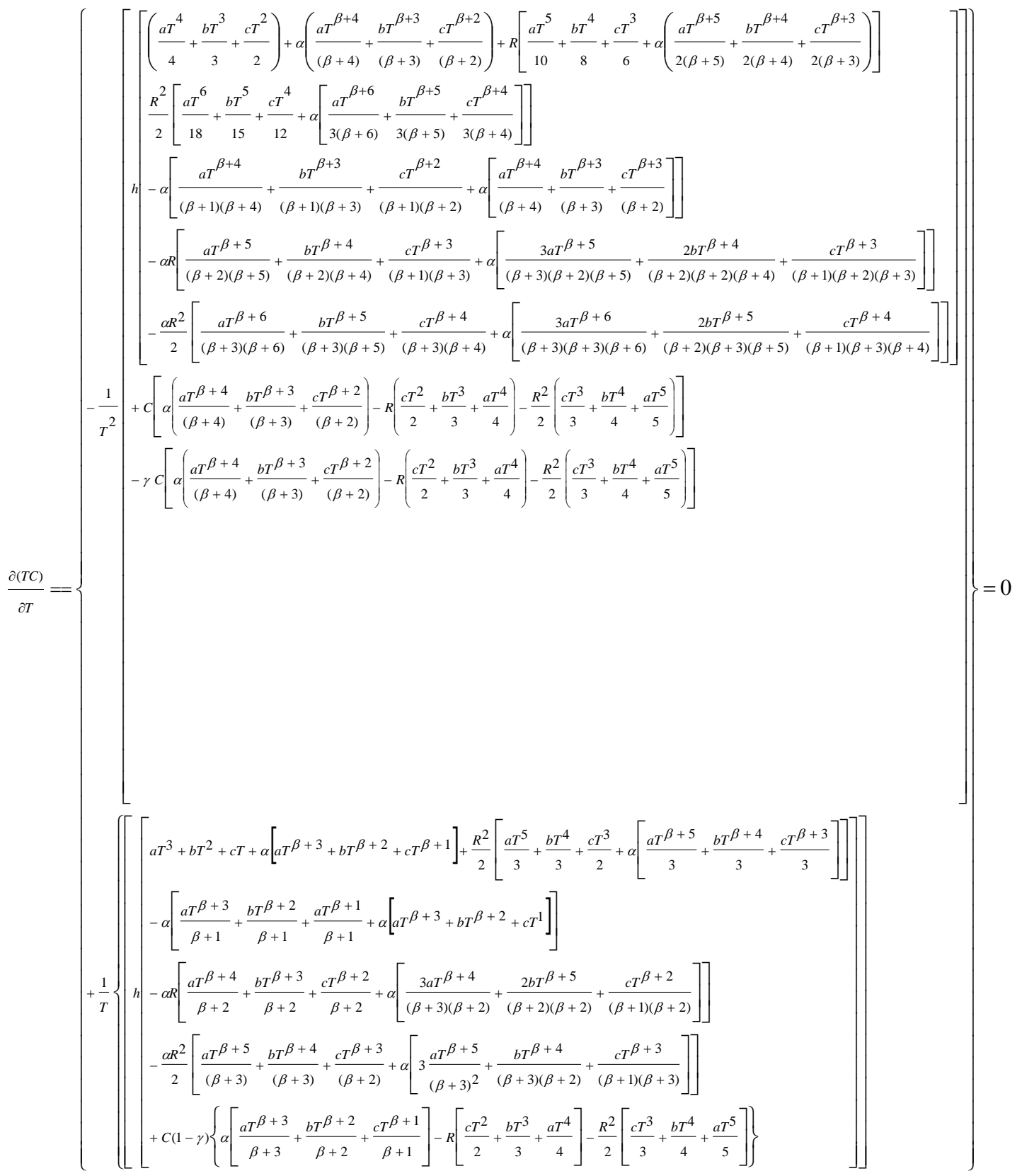

(6)

and the second derivative is $>0$. i.e.,

$$
\frac{\partial^{2}(T C)}{\partial T^{2}}>0
$$

The optimum order quantity is given by

$$
Q=\left(\frac{a T^{3}}{3}+\frac{b T^{2}}{2}+c T\right)+\alpha\left[\frac{a T^{\beta+3}}{\beta+3}+\frac{b T^{\beta+2}}{\beta+2}+\frac{c T^{\beta+1}}{\beta+1}\right]
$$

The optimum value of $\mathrm{T}$ is obtained by solving Equation (5) using MATHCAD and classified into four models. The following tables show the accelerated growth /decline models or retarded growth/decline models depending on the sign of $a$ and $b$ :

- Depending on the signs of ' $a$ ' and ' $b$ ', one may have the following different types of relative demand patterns: 
(11) $\quad a>0$ and $b<0$ gives retarded growth in demand

(1) $a<0$ and $b>0$, gives retarded decline in demand

(10) $\quad a<0$ and $b<0$ gives accelerated decline in demand.

- The above four types of demand curves are given below:

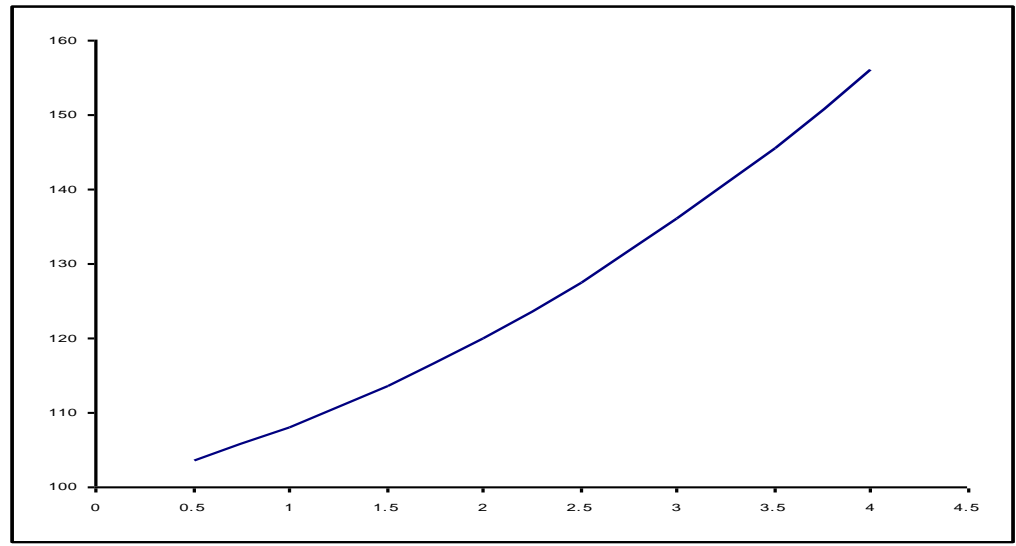

Accelerated Growth Demand Curve

Fig. 2

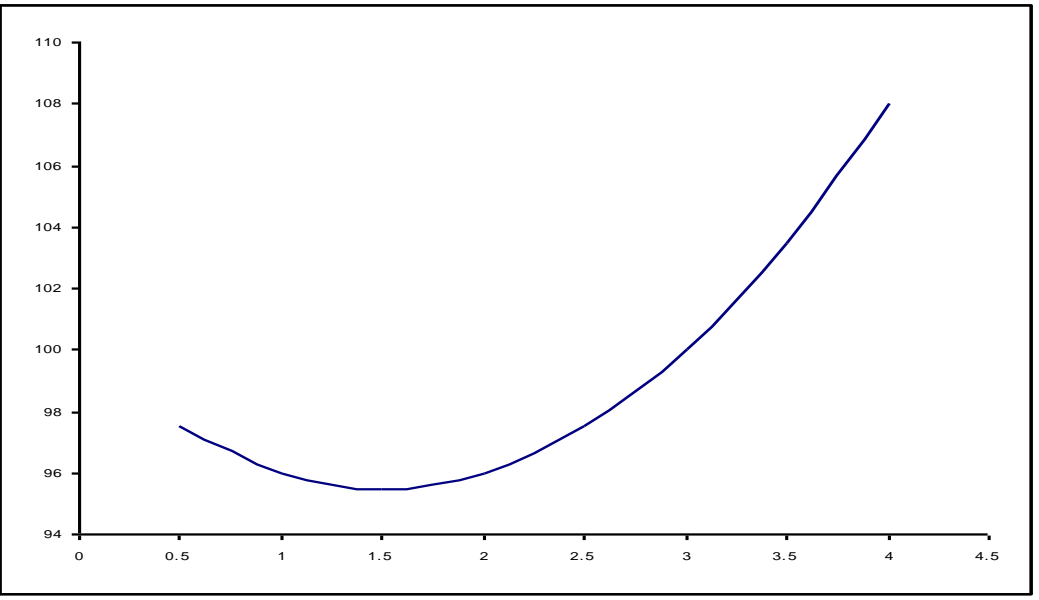

Retarded Growth Demand Curve

Fig. 3

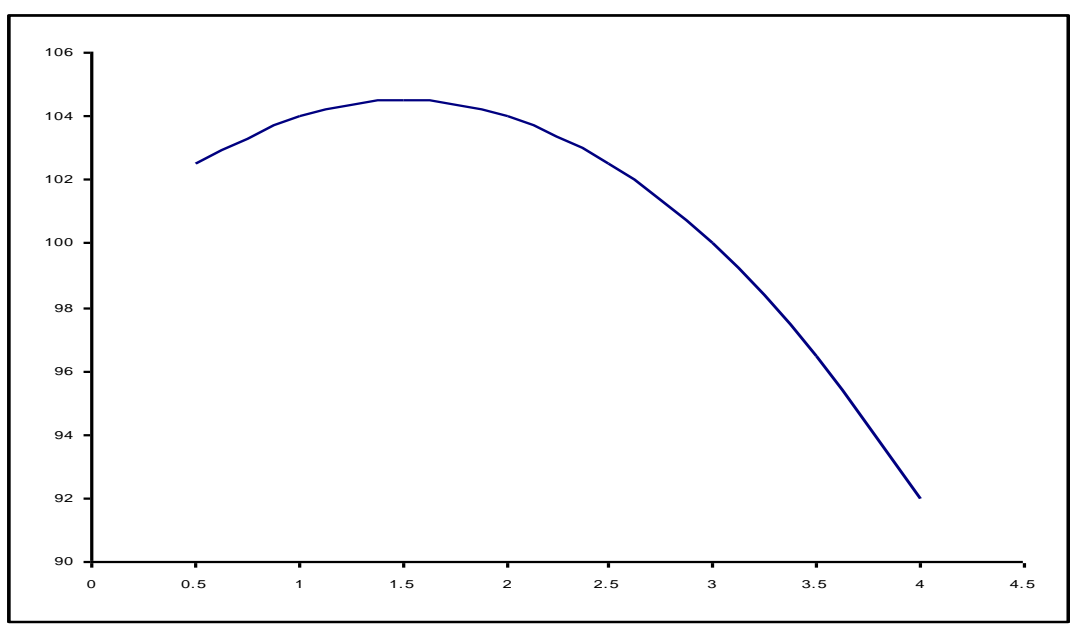

Retarded Decline Demand Curve

Fig. 4 


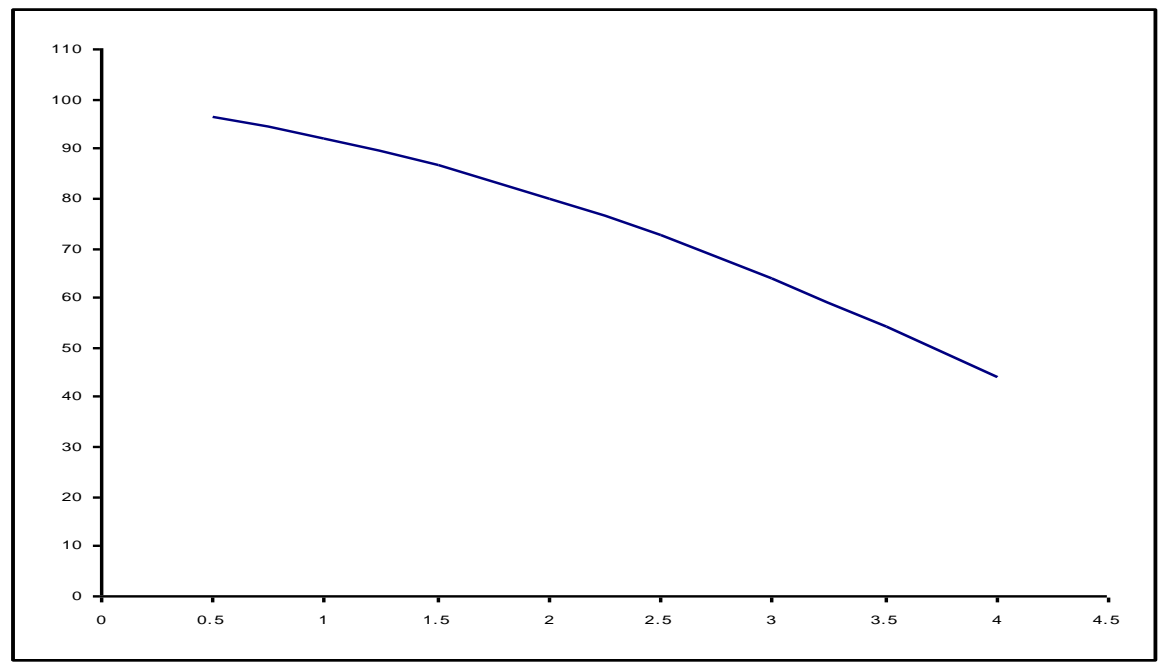

Accelerated Decline Demand Curve

Fig. 5

\subsection{Numerical Example:}

To illustrate the models developed, we assume the following data:

$$
\begin{array}{llll}
\mathrm{a}=5 & \mathrm{~b}=10 \quad \mathrm{c}=100 & \mathrm{~A}=100 & \\
\mathrm{C}=8 & \alpha=0.1 & \beta=1.5 & \gamma=0.1 \\
\mathrm{~h}=3 & \mathrm{R}=0.01 & &
\end{array}
$$

Table 1: MODEL-I: $(\mathrm{a}>0, \mathrm{~b}>0$ and $\mathrm{c}>0)$

\begin{tabular}{|l|l|l|l|}
\hline Model Type & \multicolumn{1}{|c|}{$\mathrm{T}$} & $\mathrm{Q}$ & $\mathrm{TC}$ \\
\hline Quadratic Demand & 1.635 & 200.435 & 408.664 \\
\hline Linear Demand & 1.729 & 205.512 & 397.956 \\
\hline
\end{tabular}

Table 2: MODEL-II: $(\mathrm{a}<0, \mathrm{~b}>0$ and $\mathrm{c}>0)$

\begin{tabular}{|l|l|l|l|}
\hline Model Type & \multicolumn{1}{|c|}{ T } & \multicolumn{1}{c|}{ Q } & \multicolumn{1}{c|}{ TC } \\
\hline Quadratic Demand & 1.882 & 214.936 & 384.52 \\
\hline Linear Demand & 1.729 & 205.512 & 397.956 \\
\hline
\end{tabular}

Table 3: MODEL-III: $(\mathrm{a}>0, \mathrm{~b}<0$ and $\mathrm{c}>0)$

\begin{tabular}{|l|l|l|l|}
\hline Model Type & \multicolumn{1}{|c|}{ T } & \multicolumn{1}{|c|}{ Q } & \multicolumn{1}{c|}{ TC } \\
\hline Quadratic Demand & 1.87 & 198.845 & 372.434 \\
\hline Linear Demand & 2.13 & 212.771 & 353.865 \\
\hline
\end{tabular}

Table 4: MODEL-IV: $(\mathrm{a}<0, \mathrm{~b}<0$ and $\mathrm{c}>0)$

\begin{tabular}{|l|c|c|c|}
\hline Model Type & T & Q & TC \\
\hline Quadratic Demand & - & - & - \\
\hline Linear Demand & - & - & - \\
\hline
\end{tabular}

It is observed that the Models II has shown marginal improvement in Total cost (TC) of the inventory system when comparing the quadratic time dependent demand models with linear dependent demand models when the deterioration rate follows Weibull deterioration rate. Hence we present the sensitivity analysis for the model II which is significant for further analysis. 


\subsection{Sensitivity analysis}

MODEL-II: $(\mathrm{a}<0, \mathrm{~b}>0$ and $\mathrm{c}>0)$

Table 5: Sensitivity of the scale parameter $\alpha$

\begin{tabular}{|l|l|c|l|}
\hline & T & \multicolumn{1}{|c|}{ Q } & \multicolumn{1}{c|}{ TC } \\
\hline$\alpha=0.1$ & 1.882 & 214.936 & 384.52 \\
\hline$\alpha=0.15$ & 1.675 & 196.391 & 422.282 \\
\hline$\alpha=0.2$ & 1.536 & 183.782 & 454.46 \\
\hline$\alpha=0.25$ & 1.433 & 174.359 & 482.863 \\
\hline$\alpha=0.3$ & 1.353 & 167.047 & 508.493 \\
\hline
\end{tabular}

Table 6: Sensitivity of the shape parameter $\beta$

\begin{tabular}{|l|l|l|l|}
\hline & \multicolumn{1}{|c|}{ Q } & \multicolumn{1}{c|}{ TC } \\
\hline$\beta=1.5$ & 1.882 & 214.936 & 384.52 \\
\hline$\beta=2$ & 1.686 & 191.458 & 394.243 \\
\hline$\beta=2.5$ & 1.559 & 175.848 & 401.533 \\
\hline$\beta=3$ & 1.47 & 164.716 & 407.143 \\
\hline$\beta=3.5$ & 1.406 & 156.629 & 411.568 \\
\hline
\end{tabular}

Table 7: Sensitivity of the salvage parameter $\gamma$

\begin{tabular}{|c|c|c|c|}
\hline & $T$ & Q & $\mathrm{TC}$ \\
\hline$\gamma=0.1$ & 1.882 & 214.936 & 384.52 \\
\hline$\gamma=0.15$ & 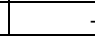 & - & - \\
\hline$\gamma=0.2$ & 7 & - & - \\
\hline$\gamma=0.25$ & 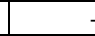 & - & - \\
\hline$\gamma=0.3$ & - & - & - \\
\hline
\end{tabular}

From Tables-5 to 7, the following points are noticed:

The total cost(TC) is more sensitive to the changes made in scale parameter and shape parameter but it does't satisfy when the salvage value greater than 0.1

\section{Discussions:}

Neglecting $\alpha^{2}$ and higher powers of $\alpha$ and putting $R=0$ the Total cost function of (5) will be reduced to 'R Venkateswarlu and R Mohan, An Inventory Model for time dependent Quadratic Demand Weibull Rate of Deterioration Rate and Salvage value Tenth AIMS International Conference on Management (Proceedings) 184-189'. When we compared this model (with inflation) and as mentioned above model the following variations are studied.

\begin{tabular}{|l|l|}
\hline $\begin{array}{l}\text { Tenth AIMS International Conference on } \\
\text { Management(Proceedings) 184-189'(without inflation) }\end{array}$ & \multicolumn{1}{|c|}{ Inventory model with inflation of this paper } \\
\hline Cycle time (T) is less & In this model cycle time is more \\
\hline The number of order quantity(Q) is less & The number of order quantity(Q) is significantly more \\
\hline Total cost is less & Total cost is significantly more \\
\hline Two models are existing & One model is existing \\
\hline
\end{tabular}

\section{Conclusions:}

We have developed inventory management models for deteriorating items when the demand rate is assumed to be quadratic function of time. It is assumed that the deterioration rate is two parameter Weibull distribution. We have solved the model without shortages under inflation.

\section{References}

[1] Buzacott J.A.,(1975) Economic Order Quantity with Inflation, Operations Research Society, Vol 26,553-558

[2] Ghrae P.M. and Schrader G.F.,(1963), An Inventory model for exponentially deteriorating items, Journal of Industrial Engineering, 14,238-243

[3] Su C.T et al, (1996) An Inventory model under inflation for stock dependent demand consumption rate and exponential decay, Opsearch Vol 20, 99-106

[4] Covert R.P and Philip G.C.,(1973) An EOQ model for items with Weibull distribution deterioration, AIIE Transactions, 5, $323-326$

[5] Aggarwal S.P (1978), A note on an order-level inventory model for a system with constant rate of deterioration, Opsearch,15, 84187

[6] Dave U. and Patel L.K., (1981) $\left(\mathrm{T}, \mathrm{S}_{\mathrm{i}}\right)$ - policy inventory model for deteriorating items with time proportional demand. Journal of Operational Research Society,32,137-142 
[7] Deb M. and Chaudhuri K.,(1987) A note on the heuristic for replenishment of trended inventories considering shortages. Journal of Operational Research Society,38,459-463

[8] Hariga M. (1995) An EOQ model for deteriorating items with shortages and time-varying demand. Journal of Operational Research Society,46,398-404

[9] Data T.K. and Pal A.K.,(1991) Effects of inflation and time value of money with linear time dependent demand rate and shortages European Journal of Operations Research Vol 52, 1-8

[10] Chakraborti T. and Chaudhuri K.S. (1996) An EOQ model for items with linear trend in demand and shortages in all cycles International Journal of Production Economics,49,205-213

[11] Giri B.C and Chaudhuri K.S. (1997) Heuristic model for deteriorating items with shortages International Journal of System Science, $28,153-159$

[12] Goyal S.K and Giri. B.C., (2001), Recent trends in modeling of deteriorating inventory European Journal of Operations research, Vol.134, pp.1-16.

[13] Mondal B., Bhunia A.K and Maiti M., (2003) An inventory system of ameliorating items for price dependent demand rate, Computers and Industrial Engineering,45(3),443-456

[14] You S.P., (2005) Inventory policy for products with price and time dependent demands, Journal of Operational Research Society, 56,870-873

[15] Ajanta Roy (2008), An Inventory model for deteriorating items with price dependant demand and time-varying holding cost, AMOAdvanced modeling and optimization, volume 10, number 1, 2008

[16] Mishra V.K and Singh L.S (2010), Deteriorating inventory model with time dependent demand and partial backlogging, Applied Mathematical sciences 4(72), 3611-3619

[17] Vinod Kumar Mishra (2012), Inventory model for time dependent holding cost and deterioration with salvage value and shortages. The Journal of Mathematics and Computer Science Vol. 4 No.1 (2012) 37-47

[18] Vikas Sharma and Rekha Rani Chaudhuri (2013), An inventory Model for deteriorating items with Weibull Deterioration with Time Dependent Demand and shortages, Research Journal of Management Sciences Vol.2(3), 28-30

[19] Mohan R. and Venkateswarlu R.,(2013a), Inventory Management Models with Variable Holding Cost and Salvage Value, IOSR J. of Busi. and Mgmt (IOSR-JBM), Vol.12(3), pp. 37-42

[20] Mohan R. and Venkateswarlu R., (2013b) Inventory Model for Time Dependent Deterioration, Time Dependent Quadratic Demand and Salvage Value, (J of In. Math.Socy, vol 81 Nos 1-2 135-146

[21] Mohan R. and Venkateswarlu R., (2013c) Inventory Management Model withQuadratic Demand, Variable Holding Cost with Salvage value,(Res J of Management Sci. Vol 2(2)

[22] Shital S. Patil, Raman Patel (2013), An Inventory Model for Weibull Deteriorating Items with Linear demand, Shortages under permissible delay in Payments and inflation, International Journal of Mathematics and Stastistics Invention Vol 1 Issue 1 Aug 2013 PP 22-30 